\title{
Glioma Subclassifications and Their Clinical Significance
}

\author{
Ricky Chen ${ }^{1} \cdot$ Matthew Smith-Cohn ${ }^{1} \cdot$ Adam L. Cohen $^{2} \cdot$ Howard Colman $^{3}$
}

Published online: 9 March 2017

(C) The American Society for Experimental NeuroTherapeutics, Inc. 2017

\begin{abstract}
The impact of targeted therapies in glioma has been modest. All the therapies that have demonstrated a significant survival benefit for gliomas in Phase III trials, including radiation, chemotherapy (temozolomide and PCV [procarbazine, lomustine, vincristine]), and tumor-treating fields, are based on nonspecific targeting of proliferating cells. Recent advances in the molecular understanding of gliomas suggest some potential reasons for the failure of more targeted therapies in gliomas. Specifically, the histologic-based glioma classification is composed of multiple different molecular subtypes with distinct biology, natural history, and prognosis. As a result of these insights, the diagnosis and classification of gliomas have recently been updated by the World Health Organization. However, these changes and other novel observations regarding glioma biomarkers and subtypes highlight several clinical challenges. First, the field is faced with the difficulty of reinterpreting the results of prior studies and retrospective data using the new classifications to clarify prognostic assessments and treatment recommendations for patients. Second, the new classifications and insights require rethinking the design and stratification of future clinical trials. Last, these observations provide the essential framework for
\end{abstract}

Howard Colman

howard.colman@hci.utah.edu

1 Department of Neurology, Clinical Neurosciences Center, University of Utah, Salt Lake City, UT, USA

2 Division of Oncology, Department of Internal Medicine, Huntsman Cancer Institute, University of Utah, Salt Lake City, UT, USA

3 Department of Neurosurgery, Huntsman Cancer Institute and Clinical Neuroscience Center, University of Utah, Salt Lake City, UT, USA the development and testing of new specific targeted therapies for particular glioma subtypes. This review aims to summarize the current literature regarding glioma subclassifications and their clinical relevance in this evolving field.

Keywords Glioma · Ependymoma · Targeted therapy · IDH mutation - MGMT methylation - TERT promoter · EGFR · BRAF $\cdot 1 \mathrm{p} / 19 \mathrm{q}$ co-deletion $\cdot 2 \mathrm{HG} \cdot \mathrm{MR}$ spectroscopy $\cdot$ Vaccine therapy

\section{Introduction}

Gliomas are the most prevalent primary tumors of the brain and spinal cord. Histologically, they share characteristics of normal glial cells and are generally named according to these similarities. However, whether gliomas originate from normal glial cells, glial or neural precursors, stem cells, or other cell types remains a topic of investigation [1]. Historically, gliomas have been diagnosed and classified based on histopathology. In the 2007 World Health Organization (WHO) classification, the main glial tumor groups included astrocytic tumors, oligodendroglial tumors, oligoastrocytic tumors, ependymal tumors, and neuronal and mixed neuronal-glial tumors (such as gangliogliomas) [2]. These groups included more circumscribed grade I tumors such as pilocytic astrocytomas, pleomorphic xanthoastrocytomas, and subependymal giant cell astrocytomas, as well as the more common infiltrating gliomas, including grade II oligodendrogliomas and astrocytomas, and grade III anaplastic oligodendrogliomas, anaplastic astrocytomas, anaplastic oligoastrocytomas, anaplastic ependymomas, and grade IV glioblastomas (GBM). The last several decades of dedicated research into the biology of gliomas has resulted in a rapidly accelerating process of discovery that has uncovered some of the key genetic and molecular underpinnings of these tumors. These observations have contributed to a new 
understanding of glioma biology that has altered the current classification and provided new insights into tumor initiation, ontogeny, and tumor progression. Later, we will explore how these findings have had a significant impact on the diagnosis and management of many different subtypes of gliomas. These findings are also opening up fertile avenues of investigation into novel therapeutic targets and approaches for specific subtypes of gliomas. In this review, we will first describe the rationale for molecular classification, then we will discuss the classification of the most common gliomas (astrocytomas and oligodendrogliomas), including rare subtypes of GBMs, next we will discuss the classification of rare types of gliomas, and we will conclude with a discussion of possible therapeutic implications of molecular classification

\section{Limitations of Histologic Classification of Gliomas}

Until recently, the standard criterion used by pathologists and neuropathologists for the diagnosis and grading of gliomas were defined in the 2007 version of the WHO classification [2]. In this classification, histologic diagnosis (designated by the aforementioned subtypes) and grading based on degrees of malignancy were the "gold standard" for diagnosis and treatment. Tumors are graded ranging from WHO grade I to grade IV, generally based on characteristics of increasing malignancy including the presence and degree of atypia and mitotic activity, as well as specific hallmarks for some subtypes such as microvascular proliferation and/or pseudopalisading necrosis in the case of GBM, which is classified as grade IV [3].

Although this histologic-based classification system has evolved from prior versions over the years and has served clinicians well, there are some limitations that have, in part, led to the recent revisions. One problem of the histologic-based diagnosis system is that it is subject to significant interobserver variability. Although studies of this question have reached different conclusions, some have shown that concordance among a group of individual neuropathologists reviewing a case can be as low as $52 \%$, with particular disagreements related to differences in classification of astrocytic versus oligodendroglioma versus oligoastrocytoma tumors, as well as interobserver differences regarding differentiation of grade II from grade III tumors [4]. Thus, the diagnostic criteria differentiating astrocytoma from oligodendroglioma are best suited for prototypic cases but may be be too practically imprecise for most tumors, which have a degree of mixed features [5]. Accurate classification by histology can be further complicated by insufficient or nonrepresentative tissue sampling [4].

Beyond the diagnostic challenges, the traditional classification and grading schemes historically lacked precision in prognosis even for patients with the same diagnosis (e.g., GBM), where survival may vary from weeks or months to multiple years. A number of clinical factors can explain some of this difference, including age, patient performance status, and extent of resection. However, even when corrected for clinical and histologic prognostic factors, we are unable to account for significant proportions of the differences in survival. These observations suggest that significant differences in underlying tumor biology within diagnoses were not accounted for in this classification. Recently, more detailed understanding of molecular alterations within gliomas have allowed for a refinement of diagnostic criteria, prognostic biomarkers, and the beginnings of our ability to utilize effective targeted therapies in molecularly defined glioma subtypes.

\section{MGMT Promoter Methylation}

An example of a molecular biomarker of glioma subtypes that has prognostic, predictive, and clinical application is $M G M T$ (O6-methylguanine-DNA methyltransferase) promoter methylation. MGMT promoter methylation was initially identified as a prognostic and predictive marker within the diagnosis of GBM in patients treated with temozolomide [6]. Temozolomide methylates purine bases, including the $\mathrm{O}^{6}$ and $\mathrm{N}^{7}$ sites on guanine and $\mathrm{N}^{3}$ site on adenine. O6-Methylguanine induction is believed to be the primary cytotoxic event, leading to the insertion of thymine instead of cytosine during cellular replication, causing double-strand breaks, failure of DNA replication, and ultimately cell death [7]. As a mismatch repair enzyme, $M G M T$ removes the O6-methylguanine adducts induced by alkylator chemotherapies, thereby abrogating their cytotoxic effects. Repair of DNA depletes the MGMT protein, which the cells must replenish. Thus, higher levels of $M G M T$ are thought to lead to temozolomide resistance [7].

Methylation of the $M G M T$ promoter in the $\mathrm{CpG}$-rich region results in epigenetic silencing (decreased expression) of the $M G M T$ protein. $M G M T$ promoter methylation is seen in approximately $40 \%$ of all GBMs [8] and can be measured through various methodologies, such as methylation microarray or bisulfate sequencing. Higher levels of $M G M T$ promoter methylation predict longer survival in GBM, particularly when temozolomide is part of the upfront therapy. In the original publication from Stupp et al. in 2005 [9], among people receiving radiation and temozolomide, $M G M T$ promoter methylation was associated with improved median survival of 21.7 months versus 12.7 months for patients with unmethylated tumors. Long-term follow-up from that initial study has substantiated this finding, with survival of $48.9 \%$ at 2 years, $27.6 \%$ at 3 years, and $13.8 \%$ at 5 years for patients with temozolomide-treated GBMs with $M G M T$ methylation versus $14.8 \%, 11.1 \%$, and $8.3 \%$, respectively, for patients with unmethylated MGMT [9]. However, while $M G M T$ promoter methylation is useful as a prognostic and predictive marker, it does not appear to define distinct diagnostic subtypes of gliomas per se. As described below, the genetic alterations in gliomas appear to be more suitable diagnostic classifiers, with 
MGMT promoter methylation occurring in all of these genetic subtypes at varying rates.

\section{Reclassification of Lower-Grade Gliomas}

As the limitations of the histopathological classifications for gliomas have become clear in view of accumulating molecular, genomic, and epigenetic data, our traditional diagnostic criteria are being reconfigured, with significant implications for diagnosis and management, as seen in Fig. 1.

The most recent reclassification of lower-grade gliomas (LGGs) is based on work by Cairncross et al. [11] that was initially published starting in the late 1990s with the identification of chromosome $1 \mathrm{p} / 19 \mathrm{q}$ loss and accelerated with more recent identification of $I D H$ mutation, ATRX mutation, and other alterations in these tumors and GBM $[12,13]$.

\section{Significance of $I D H$ Mutations in Gliomas}

The isocitrate dehydrogenase $(I D H)$ family of enzymes catalyzes the conversion of isocitate to $\alpha$-ketoglutarate while converting nicotinamide adenine dinucleotide phosphate $\left(\mathrm{NADP}^{+}\right)$to reduced NADP ${ }^{+}$(NADPH), both as part of the Kreb cycle and in the cytoplasm. Somatic mutations in genes encoding 2 of the isoforms of isocitrate dehydrogenase (IDH1 and $I D H 2$ ) are present in a variety of cancers [14]. In gliomas, they were initially identified in a high percentage of LGGs and secondary GBMs and a lower percentage of primary GBMs [12]. The vast majority of mutations are caused by an aminoacid substitution at position 132 in $I D H 1$ from arginine to histidine $(\mathrm{R} 132 \mathrm{H})$ and substitution at position 172 in $\mathrm{IDH} 2$ from arginine to lysine (R172K), although other substitutions at these or nearby sites are seen. All pathogenic mutations occur at the substate recognition site and significantly alter the enzyme active sites of the enzyme in gliomas, leading to a neomorphic change in $I D H$ function. Mutant $I D H$ genes result in proteins that convert $\alpha$-ketoglutarate to the putative oncometabolite 2-hydroxyglutarate (2HG) [15]. Not only have $I D H$ mutations been shown to be one of the earliest events in glioma formation, but the resulting production of 2HG appears to drive extensive epigenetic changes that alter cellular differentiation and could contribute to oncogenesis. However, $I D H$ mutation alone was not able to transform normal or immortalized astrocytes in culture, suggesting there are likely other contributing mechanisms [16, 17].

The majority of LGGs (65-90\%) have mutations in $I D H$ [18]. Independent of grade, the presence of $I D H$ mutations in gliomas confer significantly better progression-free survival than in their $I D H$ wild-type counterparts, irrespective of treatment received [19]. The vast majority of primary GBMs observed in older patients without any lower-grade precursor are $I D H$ wild-type, while virtually all secondary GBMs that arise from LGGs demonstrate $I D H$ mutation. This finding and the ability to examine prognosis based on $I D H$ mutation status has led to the surprising observation that many LGGs that are $I D H$ wild-type can be as aggressive as GBM and have prognoses that are quite similar to histologic grade IV tumors [20]. Some authors refer to these $I D H$ wild-type LGGs as pre-GBM or GBM-like. Conversely, GBMs that are $I D H$ mutant generally have a significantly better prognosis, not only compared with $I D H$ wild-type GBM, but also relative to $I D H$ wild-type lower grade (II-III) tumors. Detailed sequencing of individual tumors and matched initial and recurrent tumors suggests that $I D H$ mutation is a relatively early event (perhaps the initiating event) in these tumors [21]. IDH mutation is thought to be followed by other mutations such as TP53 and ATRX in
Fig. 1 A simplified algorithm for classification of the diffuse gliomas based on histological and genetic features (see text and [10] for details). A caveat to this diagram is that the diagnostic "flow" does not necessarily always proceed from histology first to molecular genetic features next, as molecular signatures can sometimes outweigh histological characteristics in achieving an "integrated" diagnosis. A similar algorithm can be followed for anaplastic-level diffuse gliomas. * Characteristic but not required for diagnosis. Reprinted with permission from the World Health Organization [10]

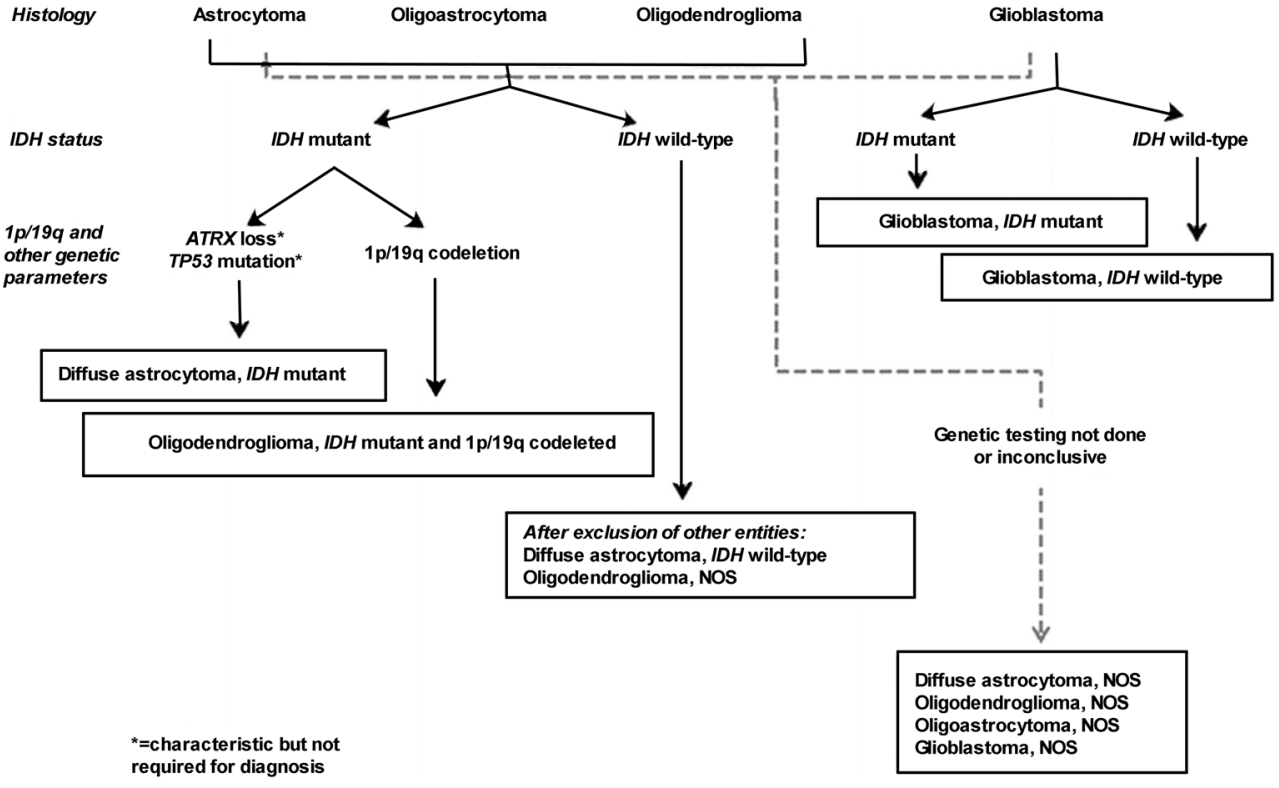


astrocytomas and co-deletion of $1 \mathrm{p} / 19 \mathrm{q}$ (potentially along with $C I C$ and FUBPI mutations) in oligodendrogliomas [22]. IDH mutant LGGs may eventually undergo malignant transformation when tertiary alterations such as KRAS, PIK3CA, PDGFRA, MET, PTEN, and N-Myc are acquired $[22,23]$. Interestingly, a 2012 study by Turcan et al. [15] found that $I D H 1$ mutations in glioma lead to genome-wide increases in DNA methylation. This hypermethylator phenotype is associated with proneural gliomas and improved survival. A very small group of $I D H$-mutated tumors lack DNA hypermethylation and have poor survival.

The mechanism of tumor initiation by $I D H$ mutation is controversial, but $I D H$ mutation has several consequences that may contribute to tumorigenesis. While the specific mechanism of $I D H$ mutation (and potentially $2 \mathrm{HG}$ ) that results in the oncogenic switch in gliomas remains unknown, potential mechanisms have been identified, including inhibition of hypoxia-related proline hydroxylases, inhibition of DNA demethylases, inhibition of histone demethylases, and alterations in glumatate metabolism. Meanwhile, reduction of the mitochondrial NADPH pool can reduce sensitivity of cells to redox associated apoptosis [24] and may also contribute to tumor progression while increasing sensitivity to oxidative damage from radiation treatment. Further work is needed to elucidate the specific role of $I D H$ mutation and the pathological consequences that clearly impact tumor evolution and prognosis.

\section{Chromosome 1p/19q Deletion}

As previously mentioned, chromosome $1 \mathrm{p} / 19 \mathrm{q}$ co-deletion has been known as a diagnostic and prognostic marker of oligodendrogliomas since 1998 [11]. More recent studies determined that the co-deletion of these 2 chromosomal arms is due to a balanced translocation between chromosomes 1 and 19 and subsequent loss of other chromosomal arms [25]. This mechanism explains why gliomas with either $1 p$ or $19 q$ deletion alone (nonconcurrent deletion) do not share the survival benefit of co-deleted tumors [26].

The initial retrospective series and subsequent retrospective analyses of large randomized trials have validated $1 p / 19 q$ deletion as a strong prognostic and predictive marker in grade II and III gliomas. In RTOG 9402, the presence of $1 p / 19 q$ codeletion in anaplastic oligodendrogliomas and oligoastrocytomas was associated with longer overall survival when treated with radiation alone ( 7.3 vs 2.7 years with intact $1 \mathrm{p} / 19 \mathrm{q}$ ). Addition of PCV (procarbazine, lomustine, vincristine) chemotherapy led to a doubling of overall survival in codeleted tumors to 14.7 years but did not change the survival for $1 \mathrm{p} / 19 \mathrm{q}$-intact tumors [27]. The EORTC 26951 from Europe presented similar chemosensitivity and favorable prognosis with $1 \mathrm{p} / 19 \mathrm{q}$ co-deleted tumors [28]. Together, these
2 trials establish chemotherapy with radiation as the standard of care for anaplastic gliomas with $1 \mathrm{p} / 19 \mathrm{q}$ co-deletion.

Although not part of the prior (2007) WHO classification system, these data were strong enough that many clinicians and neuropathologists have been using $1 \mathrm{p} / 19 \mathrm{q}$ status "informally" in the diagnosis and management of gliomas for some time. Specifically, tumors with a mixed oligoastrocytoma histology were diagnosed and treated either as astrocytoma if $1 \mathrm{p} / 19 \mathrm{q}$ intact or oligodendroglioma if $1 \mathrm{p} /$ $19 \mathrm{q}$ co-deleted. As we will explore later, this approach is now formalized in the new WHO classification system, and the prior mixed oligoastrocytoma diagnosis is only used when molecular classifiers are not available.

\section{Comprehensive Molecular Profiling of Infiltrative Gliomas}

Although the data behind molecular classification of LGGs has been building over many years and centered around identification of new single prognostic or classification markers, 2 recent landmark publications have combined these observations into a more comprehensive view of glioma molecular genetics. These findings have resulted in the recent revision of the official WHO classification of gliomas and other tumors.

The Cancer Genome Atlas Network (TCGA) effort used retrospective tumor samples from multiple centers in the US and utilized multiple molecular platforms to perform a comprehensive molecular characterization of both GBM and LGGs. The technologies used for the analysis included nextgeneration sequencing, gene expression by microarray and RNA sequencing, whole-genome methylation array, and reverse lysate protein arrays. These studies found that it is possible to subclassify LGGs into 3 main molecular groups (Table 1) [13]. The first group are IDH1/IDH2 mutated, DNA hypermethylated, and chromosome $1 \mathrm{p} / 19 \mathrm{q}$ co-deleted tumors, which carry other molecular markers that correspond to molecular oligodendrogliomas. These tumors generally have a good prognosis (median survival $\sim 7$ years in the TCGA analysis), regardless of whether they are histologically grade II or III. A second group of IDH1/IDH2 mutated and DNA hypermethylated tumors have intact $1 \mathrm{p} / 19 \mathrm{q}$, and these instead carry alterations in ATRX and TP53, corresponding to molecular astrocytomas. Their prognosis is intermediate between the molecular oligodendrogliomas and the molecular GBMs (median survival $\sim 5$ years). The last group are gliomas that are $I D H 1 / I D H 2$ wild-type, which all have intact chromosome $1 \mathrm{p} / 19 \mathrm{q}$. These tumors have poor prognosis, regardless of grade. Thus, although some of these tumors demonstrate lower histologic grade, they behave clinically as "pre-GBMs," with a prognosis of only 1.7 years median survival, which is just fractionally longer than tumors with similar molecular features and a histologic grade IV [29]. 
Table 1 The Cancer Genome Atlas Network classification of low-grade glioma

\begin{tabular}{llll}
\hline & Best prognosis & Intermediate prognosis & Worse prognosis \\
\hline$I D H$ status & Mutated & Mutated & Wild type \\
DNA methylation & Hypermethylated & Hypermethylated & NA \\
$1 \mathrm{p} / 19 \mathrm{q}$ deletion status & Deleted & Intact & Intact \\
Other mutations & NA & ATRX, TP53 & NA \\
Grade & Grade $2 / 3$ & Grade $2 / 3$ & Grade $2 / 3$ \\
\hline
\end{tabular}

$\mathrm{NA}=$ not applicable

\section{TERT Promoter Mutations}

Maintenance of telomeres is essential for cancer cells to avoid senescence and maintain proliferative potential. One mechanism for maintaining telomeres is to increase expression of the telomerase reverse transcriptase, encoded by TERT. Mutations in the promoter region of TERT increase expression and serve as an important biomarker of glioma subtypes. Large-scale analysis of over 1000 cases from databases derived from patients from University of California, San Francisco; the Mayo Clinic; and the TCGA identified 5 principal groups based on 3 molecular markers: $I D H$ mutation, $1 \mathrm{p} / 19 \mathrm{q}$ co-deletion, and TERT promoter mutation [30]. Most GBMs and GBM-like LGGs had TERT mutation only with wild-type IDH and 1p/ 19q intact. Among LGGs, tumors that carried all 3 alterations (triple-positive) typically showed oligodendroglioma histology and favorable prognosis. LGGs with only $I D H$ mutation were consistent with molecular astrocytomas and had intermediate prognosis but still had medial survival of many years. Intriguingly, the worst prognosis among LGGs is seen in those with TERT mutation only. Based on these findings, the presence of an isolated TERT mutation in a LGG may be an indicator that the clinical behavior of a tumor may be more akin to a grade IV tumor [30].

Recent evidence suggests that TERT has a dichotomous prognostic effect that may somehow enhance sensitivity to temozolomide and improve survival in the context of MGMT methylation, while conversely promoting a more resistant and prognostically worse phenotype in the context of an unmethylated MGMT. In a recent analysis from Japan [31] comparing patient outcomes and molecular subtypes, TERT promoter mutation was a poor prognostic factor only in $M G M T$ unmethylated GBM, and MGMT methylation had a larger effect on prognosis in those tumors with TERT promotor mutation than in TERT wild-type tumor. A separate analysis of a cohort of patients from University of California, Los Angeles, showed TERT promoter mutation as a prognostic factor only in tumors with $M G M T$ methylation. Similar to the Japanese cohort, MGMT methylation had a large prognostic effect on tumors with TERT promoter mutation and minimal prognostic effect on wild-type tumors [32]. Because of the correlative nature of these studies, the direction of the causal relationship between TERT and MGMT remains an open question, and the biological mechanism of this association remains unknown.

\section{Histone-Mutant Gliomas}

Sequencing of pediatric and young adult gliomas revealed additional subtypes unique to this patient population. A subset of pediatric tumors harbor mutations in the histone 3.1 and 3.3 proteins, encoded by the HISTIH3B and $H 3 F 3 A$ genes, respectively $[33,34]$. These proteins play an important role in complex post-translational epigenetic expression by mediating changes in the heterochromatin structure of DNA and directing the interactions of transcriptional activators and repressors, as well as regulation of telomeres. $H 3 F 3 A$ mutations leading to a $\mathrm{K} 27 \mathrm{M}$ substitution occur in $78 \%$ of diffuse intrinsic pontine gliomas (DIPGs) and 22\% of GBMs outside of the brainstem [34]. DIPGs without H3F3A mutations carry HIST1H3B mutations also leading to a $\mathrm{K} 27 \mathrm{M}$ substitution. Mutations of H3F $3 A$ occur predominantly in childhood gliomas (age 5-23 years) and present as midline gliomas involving thalamus, pons, and spinal cord, particularly DIPGs. A separate aminoacid substitution of glycine 34 to arginine or valine (G34R/V) in H3.3 appear mostly in pericallosal GBMs in adolescent and young adults aged 9-42 years [35]. Studies showing overlapping mutations with key established alterations in genes such as TP53, ATRX, and DAXX suggest that these hotspot mutations could be linked to the activation of distinct programs of gene expression integral to the pathogenesis of these tumors [33]. K27M mutations of $H 3 F 3 A$ in DIPGs have significant prognostic implications and are associated with worse survival than wild-type DIPGs, which by necessity carry HISTIH3B mutations [36]. Promising in vitro studies indicate these mutations may be future targets for both peptide-based vaccines and chimeric antigen receptor $\mathrm{T}$ cells $[37,38]$.

\section{The New WHO Classification of Infiltrating Gliomas}

These developments regarding the biology and classification of gliomas are so significant that the WHO elected to issue an updated WHO Classification of Tumors of the Nervous System in 2016, which was earlier than the planned update [10]. One of the key changes in this update is the inclusion of molecular diagnostic criteria for the classification of 
infiltrating gliomas. Instead of the histologic subtypes on the old classification (astrocytoma, oligodendroglioma, and oligoastrocytoma), the new criteria incorporate testing for IDH mutation, chromosome $1 \mathrm{p} / 19 \mathrm{q}$ deletion, and histone $\mathrm{mu}-$ tations. Thus, astrocytomas and GBM are divided into $I D H$ mutant and $I D H$ wild-type; oligodendrogliomas are defined as IDH mutant and 1p/19q co-deleted; and diffuse midline gliomas are defined by histone H3 K27M mutations. If molecular testing is not available, tumors are classified similarly to the prior 2007 classification, based on histology (astrocytoma, oligodendroglioma, and oligoastrocytoma), but the designation "NOS" is added to indicate that the molecular criteria are missing from the diagnosis. The differences between the 2007 and 2016 classification systems are summarized in Fig. 2.

\section{Mutational, Gene Expression, and Methylation Subtypes}

Beyond genetic and epigenetic alterations, gene-expression studies in GBM have identified several key subtypes, some of which are highly correlated with specific genetic changes. In 2006, Phillips et al. [39] published their findings of potentially 3 divisions within gliomas based on gene expression microarray: proneural, proliferative, and mesenchymal/angiogenic. The mesenchymal/angiogenic phenotype had the worst prognoses. Of 183 GBM samples examined, $31 \%$ were proneural, $20 \%$ were proliferative, and $49 \%$ were mesenchymal. Interestingly, nearly all WHO grade III tumor specimens examined $(65 / 73 ; 89 \%)$ were classified as proneural. When initial and recurrent tumors were examined from the same patient, recurrent tumors had a tendency to shift towards the mesenchymal subclass; 8 of 26 pairs of tumors (initial and reccurrence) transitioned to mesenchymal, while the remainder remained the same subclass. The precise etiology of this transition is unclear, but studies have found that radiation can convert proneural to mesenchymal subtype gliomas, a process thought to be mediated by tumor necrosis factor- $\alpha$. This transition results in radioresistance of glioma cells, perhaps in a nuclear factor $\mathrm{K}$-light-chain-enhancer of activated B cells (NFkB)-dependent manner [40].

In the 2010 TCGA classification of GBM [41], 4 gene expression subtypes were identified, based on multidimensional gene expression and genomic clustering. The gene expression subtypes were called classic, mesenchymal, proneural, and neural. In the classical subtype, 97\% of gliomas harbored high-level EGFR amplification, with $E G F R$ mutation seen in over one-third of cases. The mesenchymal subtype was characterized by higher frequency of NF1 mutations and was associated with stimulation of genes upregulating the tumor necrosis factor superfamily and NF- $\mathrm{KB}$
Fig. 2 Differences between the 2007 and 2016 World Health Organization classifification systems. Reprinted with permission from Elsevier [5]

\begin{tabular}{|c|c|}
\hline Diffuse astrocytic and oligodendroglioma tumors & Other astrocytic tumors \\
\hline Diffuse astrocytoma, $I D H$ mutant & Pilocytic astrocytoma \\
\hline Gemistocytic astrocytoma, $I D H$ mutant & Pilomyxoid astrocytoma \\
\hline Fibriltary astrocytoma & Subependymal giant cell astrocytoma \\
\hline Protoptasmic-astrocytoma & Pleomorphic xanthoastrocytoma \\
\hline Diffuse astrocytoma, $I D H$ wild-type & Anaplastic pleomorphic xanthoastrocytoma \\
\hline Diffuse astrocytoma, NOS & Ependymal tumors \\
\hline $\begin{array}{l}\text { Anaplastic astrocytoma, } I D H \text { mutant } \\
\text { Anaplastic astrocytoma, } I D H \text { wild-type } \\
\text { Anaplastic astrocytoma, NOS }\end{array}$ & $\begin{array}{l}\text { Subependymoma } \\
\text { Myxopapillary ependymoma } \\
\text { Ependymoma }\end{array}$ \\
\hline $\begin{array}{l}\text { Glioblastoma, } I D H \text { wild-type } \\
\text { Giant cell glioblastoma } \\
\text { Gliosarcoma } \\
\text { Epithelioid glioblastoma } \\
\text { Glioblastoma, } I D H \text { mutant }\end{array}$ & $\begin{array}{l}\text { Papillary ependymoma } \\
\text { Clear cell ependymoma } \\
\text { Tanycytic ependymoma } \\
\text { Ependymoma, } R E L A \text { fusion positive } \\
\text { Anaplastic ependymoma }\end{array}$ \\
\hline Glioblastoma, NOS & Other gliomas \\
\hline Gliomatosis eerebri & $\begin{array}{l}\text { Chordoid glioma of the third ventricle } \\
\text { Angiocentric glioma }\end{array}$ \\
\hline Diffuse midline glioma, H3-K27M mutant & Astroblastoma \\
\hline $\begin{array}{l}\text { Oligodendroglioma } I D H \text { mutant and } 1 \mathrm{p} / 19 \mathrm{q} \text { codeleted } \\
\text { Oligodendroglioma, NOS }\end{array}$ & Mixed neuronal-glial tumors \\
\hline $\begin{array}{l}\text { Anaplastic oligodendroglioma, } I D H \text { mutant and } 1 p / 19 q \\
\text { codeleted }\end{array}$ & $\begin{array}{l}\text { Ganglioglioma } \\
\text { Anaplastic ganglioglioma }\end{array}$ \\
\hline Anaplastic oligodendroglioma, NOS & $\begin{array}{l}\text { Desmoplastic infantile astrocytoma and ganglioglioma } \\
\text { Papillary glioneuronal tumor } \\
\text { Rosette-forming glioneuronal tumor }\end{array}$ \\
\hline $\begin{array}{l}\text { Oligoastrocytoma, NOS } \\
\text { Anaplastic oligoastrocytoma, NOS }\end{array}$ & Diffuse leptomeningeal glioneuronal tumor \\
\hline
\end{tabular}

The names of the entities/variants in blue have been omitted from the WHO 2016 classification (and are therefore crossed out). The entities/variants listed in red are new in the WHO 2016 classification, most being defined based on a combination of histologic features and molecular alterations. The abbreviation NOS (not otherwise specified) is added to the name of some already-existing entities and indicates that further molecular classification is missing (e.g., because adequate molecular analysis could not be performed). In the case of "gliomatosis cerebri," this is now considered as only a clinical/radiographic pattern of extensive infiltration, rather than a distinct entity; this pattern may be encountered in any of the newly defined integrated diffuse glioma diagnoses. In terms of fibrillary astrocytoma and cellular ependymoma, both terms are still in use, but are no longer listed in the main classification scheme, since they are considered as merely morphologic patterns rather than clinicopathologically distinct variants. 
pathways. The proneural subtype was strongly associated with PDGFRA amplifcations and IDH1 mutations, which induce the global hypermethylation phenotype called glioma-CpG island methylator phenotype (G-CIMP) [42].

DNA methylation can also be used as a classifier of molecular subtypes in GBM and LGGs, and may be useful as a more general classifier than genetic or gene expression alterations. In 2012, Sturm et al. [35] identified 6 main biological subgroups across pediatric and adult GBM, based on global DNA methylation clustering, and these methylation clusters demonstrated overlap with some of the previously described genetic and gene expression subtypes. The main methylation subtypes were $I D H$ (associated with $I D H$ mutation); $K 27$ (associated with histone $3.3 \mathrm{~K} 27$ mutation); $G 34$ (associated with histone 3.3 G34 mutation); RTK 1 "PDGFRA" (associated with increased frequency of PDGFRA amplification); mesenchymal; and RTK II "classic" (associated with higher frequency of EGFR amplification and chromosome 7 gain, and chromosome 10 loss). More recently, investigators from the TCGA effort have published a combined multiplatform analysis of GBM along with grade II and III gliomas. This analysis identified the mesenchymal and classical subtypes of GBM, as well as the subtypes of LGG described above. The previously identified proneural group clustered with $I D H$ mutated, 1p/18q non-codeleted LGGs [43]. The previously described neural subgroup was not identified. Given that neither the Phillips group nor the Sturm analysis identified a neural-like subgroup, the existence of this subgroup is controversial.

One concern with gene expression and gene methylationbased subtyping is heterogeneity over time and space. As a given biopsy, and even a good resection specimen, likely reflects only a geographic part of a diffusely infiltrating glioma, neither the histological nor the molecular approaches are capable of dealing with how heterogeneous gliomas truly are. For example, recent studies have found that different parts of GBM tumor can have different transcriptional subtypes [44]. Moreover, by analyzing gene expression patterns of paired primary and recurrent GBMs Wang et al. [45] found that two-thirds switched subtype at recurrence. These results raise questions about the clinical utility of transcriptional subtypes at our current level of knowledge about the information they provide.

\section{Rare Glioma Subtypes}

There are several other known subtypes of primary GBM that have been identified based on histology, including giant cell GBM, gliosarcoma, and the most recently identified variant epithelioid GBM [10]. Like the majority of other primary GBMs, these subtypes lack $I D H$ mutations.

Gliosarcoma is a rare form of high-grade glioma that has both sarcomatous and malignant glial components by histology and immunohistochemistry. Gliosarcoma comprises roughly $2 \%$ of all grade IV gliomas and are more prone to extracranial metastasis than other gliomas [46, 47]. A series of 19 gliosarcomas showed identical mutations in the glial and sarcomatous components, supporting a monoclonal origin for both histologic components [48]. The mutations seen are typical of GBM, including TP53 mutations, PTEN mutations/loss of heterozygosity, CDKN2A deletions, and TERT promoter mutations. Defining molecular alterations or targetable molecular alterations common in gliosarcoma have not been identified.

Giant cell GBMs constitute $1 \%$ to $5 \%$ of all GBMs, and are characterized by a predominance of bizarre, multinucleated giant cells $[2,49]$. The median age at diagnosis is about 44 years [50]. TP53 mutations are common (78-90\%), while epidermal growth factor receptor (EGFR) amplification is rare. Alterations of PTEN can occur via both mutation (33\%) or loss of heterozygosity at $10 \mathrm{q}(50 \%)$ [50]. However, despite the young age of diagnosis and high rate of TP53 mutations, giant cell GBMs are distinct from typical secondary GBMs based on a short length of prediagnosis symptoms and lack of IDH and ATRX mutations. In a recent study by Erson-Omay et al. [51], 6 of 720 exomesequenced glioma samples harbored somatic mutations in the exonuclease domain of the polymerase epsilon gene (POLE). This mutation was found to cause ultramutated giant cell highgrade glioma subtype with a better prognosis (26.93 vs 6.93 months of progression-free survival). Histologically, POLE mutant tumors harbored multinucleated giant or bizarre cells and had a tendency to be infiltrated by immune cells. Similarly, a study looking at colorectal cancers with this mutation [52] also found better prognosis and found increased infiltration of immune cells predominantly comprised of $\mathrm{CD} 8^{+}$lymphocyte effector cytokines, indicating the mutation was associated with increased immunogenicity. Studies have suggested that tumors with mismatch repair deficiency, which by extension include hypermutator phenotype gliomas such as those with POLE mutations, have a marked increase in the number of mutation-associated neoantigens, thereby producing more potential targets of endogenous T-cell responses. Furthermore, immune checkpoint inhibitors such as pembrolizumab may have increased efficiency in these tumors [53].

One of the newest additions to the updated 2016 WHO tumor classification guidelines, epithelioid GBMs are distinguished histologically by epithelioid cells with abundant cytoplasm, prominent nucleoli, and rhabdoid cells $[10,54]$. They typically occur in the first 3 decades of life [55], with 1 study [56] comprised of 6 patients finding a median age at diagnosis of 7.6 years and a median survival of 169 days. Although the rhabdoid appearance can lead to confusion with atypical teratoid rhaboid tumor, epithelioid GBMs maintain expression of INI1 [57]. Unique to this subgroup are $B R A F^{\mathrm{V} 600 \mathrm{E}}$ mutations (50\%) and frequent hemizygous deletions of ODZ3 [58]. There have also been case reports with TERT promotor mutations [59]. Also suggesting a unique molecular basis for epithelioid GBM, this subclass of GBM does not harbor 
alterations typically seen in primary GBMs such as $E G F R$ amplification and chromosome 10 loss [10].

Other glioma subtypes are also characterized by high rates of $B R A F^{V 600 E}$ mutations. Pleomorphic xanthoastrocytoma (PXA), like epithelioid GBM, occurs mainly in children and adults under the age of 30 years [60]. Histologically, PXA is characterized by pleomorphic giant cells, xanthomatous cytoplasm, and infiltration with reticulin and lymphocytes. Up to two-thirds of PXAs carry $B R A F^{V 600 E}$ mutations $[61,62]$. The presence of a $B R A F^{V 600 E}$ mutation may help distinguish a PXA from a giant cell GBM, which is important given the marked prognostic difference between the two. Gangliogliomas are mixed glioneuronal tumors and are the most common neoplasm causing chronic focal epilepsy in young patients [63]. BRAF ${ }^{V 600 E}$ mutation can be seen in $20 \%$ to $50 \%$ of gangliogliomas of the brain $[62,64]$. Pilocytic astrocytomas make up $20 \%$ of pediatric brain tumors and appear to have about a $9 \%$ rate of $B R A F^{V 600 E}$ mutation [65]. This mutation was found to be associated with extracerebellar location. The therapeutic implications of $B R A F$ mutations are discussed at the end of this review.

\section{Ependymomas}

Ependymomas make up 3\% of all primary central nervous system tumors [66]. Ependymomas are histologically identified based on perivascular pseudorosettes and true ependymal rosettes [67]. The 10 -year overall survival is about $64 \%$ in pediatric patients and ranges from $70 \%$ to $89 \%$ in adult patients [68]. The current standard of care is surgical resection and radiation therapy [69]; there have been no systemic therapies to date with proven survival benefit [70]. Ependymomas have historically been classified based on location, grade, and histology.
Supratentorial location and high grade are independent predictors of poor progression-free survival [71].

Histologically, ependymoma grades are determined based on features similar to other malignancies, including mitotic figures, cellular pleomorphism, and invasion into tissue. The grade I group consists of subependymomas and myxopapillary ependymomas, grade II of ependymomas, and grade III of anaplastic ependymomas. Grade III ependymomas are associated with higher risk of drop metastasis [66]. The new 2016 WHO classification of tumors of the central nervous system maintains the majority of the prior histologic ependymoma diagnoses, but recognizes a new genetically defined ependymoma subtype known as RELA fusion-positive [10].

In 2015, Pajtler et al. [72] used 500 ependymomas to classify molecularly ependymal tumors. Excluding myxopapillary ependymomas and subependymomas, they found 5 molecular groups of ependymomas, with 1 subgroup in the spine and 2 each in the supratentorial brain and posterior fossa (Fig. 3).

Spine ependymomas form a distinct clinical group with an age distribution higher than other ependymomas [73]. Most spine WHO grade II or III ependymoma have chromosomal instability and mutations in $N F 2$. This finding is consistent with prior work showing germline and sporatic mutations of $N F 2$ are associated with spinal ependymomas [73].

Within the posterior fossa, Pajtler et al. [72] identified 2 groups, which had been previously identified using clinical and molecular criteria by Witt et al. [74] and Mack et al. [75]. These groups have been referred to as group A and Group B. Group A is characterized by young age, poor prognosis, and a hypermethylated CIMP phenotype. Group B is characterized by older age, including adults, better prognosis, chromosome instability, and lack of a CIMP phenotype. These differences are not recognized by the 2016 WHO classification.
Fig. 3 Subgroups of ependymoma and their molecular characteristics by location in the neuroaxis. Reprinted with permission from [67]

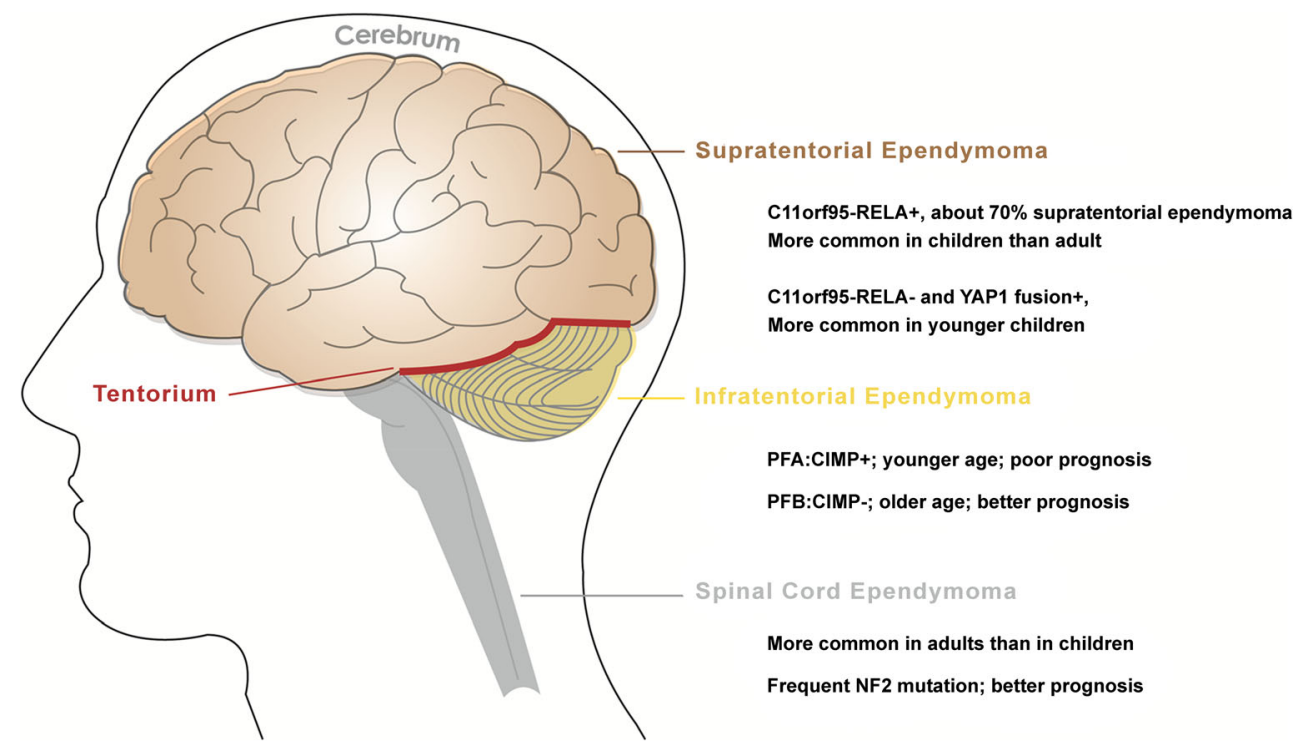


The supratentorial group of ependymomas can be divided based on alterations in RELA and YAP1. In 2014, Parker et al. [76] found that fusions involving RELA are driver mutations for about two-thirds of supratentorial ependymomas. RELA is the principal effector of canonical NF- $\mathrm{KB}$ signalling, and it is most commonly fused to an uncharacterized gene, C11orf95. The C11orf95-RELA fusions resulted from chromothripsis (an event characterized by a multitude of clustered genome rearrangements of chromosomes [77]) involving chromosome 11q13. Supratentorial ependymomas without RELA fusions have fusions involving the transcription factor $Y A P 1$, often with FAM118B or MAMLD1. YAP1 fusion is associated with a better prognosis than RELA fusion-associated ependymomas. Neither of these alterations impacts treatment yet.

\section{Clinical Applications}

The rapidly evolving understanding of the molecular subtypes of gliomas has a number of clinical implications and applications (Table 2). These applications include diagnostic imaging, pathologic testing requirements, clinical trial planning, and targeted treatment of gliomas.

\section{Novel Imaging}

The increased levels of $2 \mathrm{HG}$ within $I D H$-mutated gliomas can be used as a biomarker via noninvasive imaging. Magnetic resonance spectroscopy has been shown in multiple studies to detect elevated $2 \mathrm{HG}$ levels and in the future may be able to identify reliably a tumor's $I D H$ mutation status without need of a biopsy $[78,79]$. This novel technique has potential for preoperative determination of $I D H$ mutation status in a suspected glioma, which may facilitate neurosurgical planning for the desired extent of resection [80]. One recent retrospective series indicated that the prognostic associations of extent of resection of enhancing and nonenhancing portions of gliomas had significant differences based on $I D H$ mutation status. While extent of resection of enhancing disease was associated with better outcome in $I D H$ wild-type gliomas, larger volumetric resection of nonenhancing disease had a significant impact on survival only in the $I D H$-mutant tumors [80]. As new therapies develop targeting IDH1 mutations, $2 \mathrm{HG}$ magnetic resonance imaging spectroscopy has the potential to act as a pharmocodynamic biomarker, providing a noninvasive measure of a treatment's efficacy. Further exploration and validation is needed to refine the technology for

Table 2 Emerging targeted therapies for glioma subtypes

\begin{tabular}{|c|c|c|c|}
\hline Subtype & Markers & Median age (years) & Emerging targeted therapies \\
\hline Mesenchymal Glioblastoma & $\begin{array}{l}N F 1 \text { deletion } \\
N F-\text { kappaB activation }\end{array}$ & 58 & Trametinib \\
\hline Classical glioblastoma & $E G F R$ amplification & 56 & $\begin{array}{l}\text { Erlotinib } \\
\text { EGFR vaccines } \\
\text { Anti-EGFR antibody-drug conjugates }\end{array}$ \\
\hline Proneural/IDH mutant Glioblastoma & $\begin{array}{l}I D H \text { mutation } \\
G \text {-CIMP phenotype }\end{array}$ & 52 & $\begin{array}{l}\text { IDH vaccine } \\
\text { IDH inhibitors } \\
\text { Glutaminase inhibitors } \\
\text { Checkpoint inhibitors }\end{array}$ \\
\hline Midline gliomas & $H 3 F 3 A K 27 M$ mutation & $5-11$ & H3F3A K27M vaccine \\
\hline Proneural/RTK glioblastomas & PDGFRA amplification & & Sunitinib \\
\hline Epithelioid glioblastoma & $\begin{array}{l}B R A F^{V 600 E} \\
O D Z 3 \text { deletion }\end{array}$ & 8 & $\begin{array}{l}\text { Dabrafenib } \\
\text { Vemurafenib }\end{array}$ \\
\hline Pilocytic astrocytoma & $B R A F$ fusion & $5-14$ & Sorafenib \\
\hline Giant cell glioblastoma & $\begin{array}{l}\text { TP53 mutation } \\
\text { POLE mutation }\end{array}$ & 44 & Immune checkpoint inhibitors \\
\hline Diffuse astrocytoma & $\begin{array}{l}\text { IDH mutation } \\
\text { ATR } X \text { mutation } \\
\text { TP53 mutation }\end{array}$ & 36 & $\begin{array}{l}\text { IDH vaccine } \\
\text { IDH inhibitors }\end{array}$ \\
\hline Diffuse oligodendroglioma & $\begin{array}{l}\text { IDH mutation } \\
1 p 19 q \text { deletion } \\
C I C \text { or } F U B P 1 \text { mutation }\end{array}$ & $35-44$ & $\begin{array}{l}\text { IDH vaccine } \\
\text { IDH inhibitors }\end{array}$ \\
\hline Preglioblastoma & $\begin{array}{l}\text { IDH wild type } \\
\text { TERT promoter mutation }\end{array}$ & & Imetelstat \\
\hline Pleomorphic xanthoastrocytoma & $B R A F^{V 600 E}$ mutation & 22 & $\begin{array}{l}\text { Dabrafenib } \\
\text { Vemurafenib }\end{array}$ \\
\hline Gangliogliomas & $B R A F^{V 600 E}$ mutation & $9-25$ & $\begin{array}{l}\text { Dabrafenib } \\
\text { Vemurafenib }\end{array}$ \\
\hline
\end{tabular}

EGFR $=$ endothelial growth factor receptor; IDH = isocitrate dehydrogenase 
accurate quantification of the metabolite over time and avoidance of false-positives and -negatives [81].

\section{Refining Routine Diagnostic Practices to Aid in Prognosis}

The newly revised WHO criteria for classification and grading of gliomas reflects a paradigm shift in the diagnosis and management for these tumors by encouraging integration of genomic data into the standard diagnostic workup. Routine testing of $1 \mathrm{p} / 19 \mathrm{q}$ co-deletion by fluorescent in situ hybridization and immunostaining for loss of $A T R X$ is needed to delineate oligodendrogliomas from astrocytomas, resolving the frequent ambiguity of mixed features on histology. Similarly, IDH mutation status should be ascertained for every oligodendroglioma and astrocytoma, irrespective of grade by immunostaining or genetic sequencing where immunohistochemical testing is initially negative. For potential PXAs, pilocytic astrocytomas, gangliogliomas, epitheliod GBMs, rhabdoid meningiomas, and astrocytic tumors before the age of 30 years, $B R A F^{V 600 E}$ testing should be done [82]. These tests allow for accurate diagnosis and prognostication. This array of molecular information can be used to examine and synthesize a case by correlation with the clinical context, imaging features, and histology so as to draw up the best possible representation of a given tumor's biology. This arms clinicians with powerful information that often greatly increases confidence in the diagnosis, which may lead to improved management strategies.

In certain situations, unique features in the case can also prompt further testing that may, in fact, alter the diagnosis and carry prognostic implications. One conceivable and illustrative example might be a nonenhancing brainstem tumor biopsied in a young adult patient that was given the diagnosis of "grade II astrocytoma" but mutation in $I D H$ was lackinghighly atypical in a LGG of younger onset. Further testing may reveal the presence of $H 3 F 3 A K 27 M$ mutation, which is associated with DIPG. Though more prevalent in children, DIPGs occasionally present later in life and histologically convey a spectrum of findings that could be consistent with different glioma types and grades [83]. This molecular finding would thus portend a worse prognosis than expected from the histology. From a management perspective, such a tumor might be treated more like a pediatric DIPG, where the standard of care is radiotherapy alone, rather than like an adult GBM, although further study on optimal treatment of each molecular subtype is needed [84].

\section{Therapeutics and Clinical Trial Planning}

\section{Testing New Targeted Therapies in Defined Subgroups}

Prior to molecular classification, clinical trials for patients with glioma were stratified by clinical variables, meaning prior trials were unknowingly populated by patients whose tumors had similar morphology but diverse molecular and genetic profiles. Given our current understanding of the molecular data, the unseen variation in molecular alterations (and hence varied prognoses and underlying biology) within groups of tumors in prior trials potentially diluted the power of the studies and obscured the detection of possible treatment effects. Presumably, certain therapies may show clinical activity only in certain molecular subgroups. The phase III AVAglio study of bevacizumab for newly diagnosed GBM found no overall survival benefit in the population of all patients with GBM [85], but a post-hoc analysis did identify a potential survival increase (17.1 vs 12.8 months) within the proneural IDH1 wild-type GBM subgroup [86], warranting further study.

In diffuse glioma, EGFR amplification and MGMT methylation define specific subpopulations against which to test new therapies targeted to those markers. EGFR is a receptor tyrosine kinase that activates $P 13 / A K T$ mitogenic pathways, resulting in activation of $M T O R$, an enzyme that is key to increase angiogenesis, proliferation, and survival of tumor cells [87]. In GBM, EGFR is overexpressed in 50\% to $60 \%$ of patients, and $30 \%$ of patients harbor a specific deletion called epidermal growth factor receptor variant III (EGFRvIII), which is an independent negative prognostic indicator [88]. Despite success in lung cancer, EGFR tyrosine kinase inhibitors such as gefitinib and erlotinib produced no survival benefit in phase II trials of EGFR-amplified GBM $[89,90]$. Cetuximab, a high-affinity monoclonal antibody that binds EGFR and causes destruction of the receptor, also failed to show clinical activity combined with chemotherapy [91]. The anti-EGFR $I I I$ vaccine, rindopepimut, showed promise in earlier studies but failed to improve survival in the recent phase III ACTIV trial [92]. Thus, unfortunately, despite great promise, we have yet to uncover any effective therapies targeting EGFR in gliomas. It is unclear whether these failures in EGFR-targeted therapy are owing to limits of brain penetration, differences in the specific mutations in gliomas compared with other cancers, redundant activating pathways or escape mechanisms, or intratumoral heterogeneity. Ongoing studies of EGFR-targeting therapies include a promising monoclonal antibody specifically engineered for the EGFRvIII mutant receptor that is in phase I trials of GBM [93] and an antibody-drug conjugate targeting activated $E G F R$ that is in a phase III trial in EGFR-amplified GBM [94]. Additionally, development of the clinical applications of humanized anti-EGFR variant III chimeric antigen receptor T cells is currently being explored [95].

Another established marker important to clinical trials is the methylation of the $M G M T$ promoter. As discussed, $M G M T$ promoter methylation serves as a predictor of outcome and enhances sensitivity to temozolomide treatment through the suppression of DNA repair enzyme, MGMT. In addition, 
this epigenetic marker is being used as a basis for targeted therapies. For example, there are current phase II/III clinical trials of a poly-adenosine diphosphate ribose polymerase inhibitor, veliparib, that disrupts an alternative pathway of DNA repair (base excision repair) combined with temozolomide in people with newly diagnosed $M G M T$ methylated GBMs [96]. However, as the survival benefit from temozolomide for patients with GBMs that are MGMT unmethylated is significantly less than for those whose tumors are methylated, this subpopulation stands in even greater need of effective nonalkylating therapies. For this reason, some clinical trials enrolling patients with newly diagnosed GBM require $M G M T$ unmethylated status as their main eligibility criteria.

\section{Treatments Targeting IDH Mutations}

Treatments targeting $I D H$-mutated tumors are in clinical trials. Strategies include directly targeting $I D H$ through small molecular $I D H$ inhibitors or $I D H$-targeted vaccines [97]. Other strategies target metabolic consequences of $I D H$ mutations, such as dependence on glutaminase [98].

\section{Use of Existing Targeted Agents in Tumors With Specific Mutations}

Gliomas that harbor the $B R A F^{V 600 E}$ may be sensitive to drugs targeting this mutation. BRAF is a serine/threonine protein kinase that plays an integral role in cell differentiation, growth, and proliferation through its role in the Ras/Raf/MEK/extracellular regulated kinase pathway [99, 100]. Studies on $B R A F^{V 600 E}$ mutant melanomas have found success with the $B R A F$ inhibitors dabrafenib or vemurafenib [101]. Experience with these agents in gliomas with $B R A F^{V 600 E}$ mutations are mostly limited to small case reports. Treatment of recurrent gangliogliomas with the BRAF inhibitor dabrafanib led to a partial response in 1 of 3 patients with progression-free survival ranging from 4 to 10 months [102]. Several case reports have demonstrated responses to vemurafenib of gangliogliomas with $B R A F^{V 600 E}$ mutations [103-105]. Two case reports of treating children with epithelioid GBMs harboring $B R A F^{V G O O E}$ mutations with vemurafenib have shown responses or long-term progression-free intervals [106, 107]. Multiple case reports have now been published with responses of PXA to $B R A F$-targeted treatment, such as vemurafenib [107-110]. Thus, $B R A F^{V 600 E}$-targeted therapy is very promising in selected subsets of gliomas.

Several ongoing trials are testing treating tumors with targetable mutations, such as $B R A F^{V 600 E}$, with targeted drugs independent of histology. The National Cancer Institutesponsored Molecular Analysis for Therapy Choice (NCIMATCH) trial and the American Society of Clinical Oncology (ASCO)-sponsored Testing the Use of Food and Drug Administration (FDA) Approved Drugs That Target a
Specific Abnormality in a Tumor Gene in People With Advanced Stage Cancer (TAPUR) trial are phase II umbrella trials that enroll patients on the basis of genetic events rather than tumor history. For example, patients with brain tumors with mutations involving neurofibromin mutations, $\mathrm{PI} 3 \mathrm{~K} \alpha$, and phosphatase and tensin homologue mammalian target of rapamycin mutations and tuberous sclerosis complex mutations can qualify for trial of targeted therapies for these mutations (NCT02465060, NCT02693535). GBM-specific trials matching treatments to particular mutations, such as the Individualized Screening Trial of Innovative Glioblastoma Therapy (INSIGHT) trial (NCT02977780), are expected in the near future.

\section{Molecular Markers Assisting in Understanding and Overcoming Mechanisms of Treatment Resistance}

Molecular studies have helped us to investigate the mechanisms of tumoral resistance against standard clinical treatments and illuminate the potential genetic events involved in developing recurrent, progressive disease. Mutational analysis by sequencing of tissue samples in patients with low-grade astrocytomas at initial resection and subsequent resections for recurrent tumor have revealed linear and branching patterns of mutational evolution traceable in most cases by shared mutations to a single original clone [111]. In such cases, IDHI mutation was the only shared mutation identified across all the patients studied, which not only implicates IDH1 mutation as a pivotal inciting event in gliomagenesis, but also supports the potential for targeted therapies against IDHI [111]. These studies have found that treatment with the alkylator temozolomide, the most common chemotherapy for gliomas comprising standard of care, was associated with eventual development of hypermutated, temozolomide-resistant tumors in 6 of 10 patients studied [111]. Many of these hypermutated tumors developed mutations in the tumor suppressor gene retinoblastoma and Akt-mammalian target of rapamycin pathway apparently after treatment with temozolomide, implicating these specific driver mutations for malignant transformation into secondary GBM. Follow-up studies have also uncovered an association between mutations in mismatch repair genes or mismatch repair silencing by MGMT methylation and development of hypermutator tumors after temozolomide therapy [112]. As discussed above, targeting these hypermutated tumors with checkpoint inhibitors or other immunotherapy is an area of active study in gliomas as in other solid tumors.

\section{Conclusion}

The classification of GBMs into subtypes based on genomic, epigenomic, and proteomic profiles has come a long way. In addition to changing the way gliomas are being diagnosed, 
molecular analyses have deepened our understanding of their underlying biology. Discoveries of multiple biologically and prognostically important markers have led to new categorizations of gliomas. Moreover, there are many promising therapies targeted to specific pathways essential to tumor activity. Clinical trials can now utilize molecular stratification to harness greater statistical power to detect possible treatment effects of the new agents. However, the promise of this new molecular era is still limited by our current understanding and the need for more and better therapies to target alterations in gliomas

\section{References}

1. Modrek AS, Bayin NS, Placantonakis DG. Brain stem cells as the cell of origin in glioma. World J Stem Cells 2014;6:43-52.

2. Louis DN, Ohgaki H, Wiestler OD, et al. The 2007 WHO classification of tumours of the central nervous system. Acta Neuropathol 2007;114:547-547.

3. Cahill DP, Sloan AE, Nahed BV, et al. The role of neuropathology in the management of patients with diffuse low grade glioma. $\mathrm{J}$ Neurooncol 2015;125:531-549.

4. Coons SW, Johnson PC, Scheithauer BW, Yates AJ, Pearl DK. Improving diagnostic accuracy and interobserver concordance in the classification and grading of primary gliomas. Cancer 1997;79:1381-1393.

5. Perry A, Wesseling P. Histologic classification of gliomas. 1st ed. Elsevier B.V; 2016.

6. Hegi ME, Diserens A-C, Gorlia T, et al. MGMT gene silencing and benefit from temozolomide in glioblastoma. N Engl J Med 2005;352:997-1003.

7. Zhang J, Stevens MFG, Bradshaw TD. Temozolomide: mechanisms of action, repair and resistance. Curr Mol Pharmacol 2012;5:102-114.

8. Esteller M, Garcia-Foncillas J, Andion E, et al. Inactivation of the DNA-repair gene MGMT and the clinical response of gliomas to alkylating agents. N Engl J Med 2000;343:1350-1354.

9. Stupp R, Hegi ME, Mason WP, et al. Effects of radiotherapy with concomitant and adjuvant temozolomide versus radiotherapy alone on survival in glioblastoma in a randomised phase III study: 5-year analysis of the EORTC-NCIC trial. Lancet Oncol 2009;10:459-466.

10. Louis DN, Perry A, Reifenberger G, et al. The 2016 World Health Organization Classification of Tumors of the Central Nervous System: a summary. Acta Neuropathol 2016;131:803-820.

11. Cairncross JG, Ueki K, Zlatescu MC, et al. Specific genetic predictors of chemotherapeutic response and survival in patients with anaplastic oligodendrogliomas. J Natl Cancer Inst 1998;90:14731479.

12. Yan H, Friedman A, Reardon D, Herndon J. IDH1 and IDH2 mutations in gliomas. N Engl J Med 2009;360:765-773.

13. The Cancer Genome Atlas Research Network. Comprehensive, integrative genomic analysis of diffuse lower-grade gliomas. N Engl J Med 2015;372:2481-2498.

14. Yang H, Ye D, Guan KL, Xiong Y. IDH1 and IDH2 mutations in tumorigenesis: mechanistic insights and clinical perspectives. Clin Cancer Res 2012;18:5562-5571.

15. Thompson CB. Metabolic enzymes as oncogenes or tumor suppressors. N Engl J Med 2009;360:813-815.
16. Turcan S, Rohle D, Goenka A, et al. IDH1 mutation is sufficient to establish the glioma hypermethylator phenotype. Nature 2012;483:479-483.

17. Lu C, Ward PS, Kapoor GS, et al. IDH mutation impairs histone demethylation and results in a block to cell differentiation. Nature 2012;483:474-478.

18. Sun H, Yin L, Li S, et al. Prognostic significance of IDH mutation in adult low-grade gliomas: a meta-analysis. J Neurooncol 2013;113:277-284.

19. Wick W, Hartmann C, Engel C, et al. NOA-04 Randomized phase III trial of sequential radiochemotherapy of anaplastic glioma with procarbazine, lomustine, and vincristine or temozolomide. J Clin Oncol 2009;27:5874-5880.

20. Dunn GP, Andronesi OC, Cahill DP. From genomics to the clinic: biological and translational insights of mutant IDH 1/2 in glioma. Neurosurg Focus 2013;34:1-15.

21. Suzuki H, Aoki K, Chiba K, et al. Mutational landscape and clonal architecture in grade II and III gliomas. Nat Genet 2015;47:458-468.

22. Wakimoto H, Tanaka S, Curry WT, et al. Targetable Signaling Pathway Mutations Are Associated with Malignant Phenotype in IDH-mutant gliomas. Clin Cancer Res 2014;20:2898-2909.

23. Cohen A, Sato M, Aldape K, et al. DNA copy number analysis of Grade II-III and Grade IV gliomas reveals differences in molecular ontogeny including chromothripsis associated with IDH mutation status. Acta Neuropathol Commun 2015;3:34.

24. Oizel K, Gratas C, Nadaradjane A, Oliver L, Vallette FM, Pecqueur C. D-2-Hydroxyglutarate does not mimic all the IDH mutation effects, in particular the reduced etoposide- triggered apoptosis mediated by an alteration in mitochondrial NADH. Cell Death Dis 2015;6:e1704-e1710.

25. Jenkins RB, Blair H, Ballman KV, et al. A t $(1 ; 19)(q 10 ; p 10)$ mediates the combined deletions of $1 p$ and $19 q$ and predicts a better prognosis of patients with oligodendroglioma. Cancer Res 2006;66:9852-9861.

26. Vogazianou AP, Chan R, Backlund LM, et al. Distinct patterns of $1 p$ and $19 q$ alterations identify subtypes of human gliomas that have different prognoses. Neuro Oncol 2010;12:664-678.

27. Cairncross G, Wang M, Shaw E, et al. Phase III trial of chemoradiotherapy for anaplastic oligodendroglioma: long-term results of RTOG 9402. J Clin Oncol 2013;31:337-343.

28. van den Bent MJ, Brandes AA, Taphoorn MJB, et al. Adjuvant procarbazine, lomustine, and vincristine chemotherapy in newly diagnosed anaplastic oligodendroglioma: long-term follow-up of EORTC Brain Tumor Group study 26951. J Clin Oncol 2013;31: 344-350.

29. Brennan CW, Verhaak RGW, McKenna A, et al. The somatic genomic landscape of glioblastoma. Cell 2013;155:462-477.

30. Eckel-Passow JE, Lachance DH, Molinaro AM, et al. Glioma groups based on $1 \mathrm{p} / 19 \mathrm{q}, I D H$, and TERT promoter mutations in tumors. N Engl J Med 2015;372:2499-2508.

31. Arita H, Yamasaki K, Matsushita Y, et al. A combination of TERT promoter mutation and MGMT methylation status predicts clinically relevant subgroups of newly diagnosed glioblastomas. Acta Neuropathol Commun 2016;4:1-14.

32. Nguyen HN, Lie A, Li T, et al. Human TERT promoter mutation enables survival advantage from MGMT promoter methylation in IDH1wild-type primary glioblastoma treated by standard chemoradiotherapy. Neuro Oncol 2017;19:394404.

33. Schwartzentruber J, Korshunov A, Liu X-Y, et al. Driver mutations in histone $\mathrm{H} 3.3$ and chromatin remodelling genes in paediatric glioblastoma. Nature 2012;482:226-231.

34. Wu G, Broniscer A, McEachron TA, et al. Somatic histone H3 alterations in pediatric diffuse intrinsic pontine gliomas and nonbrainstem glioblastomas. Nat Genet 2012;44:251-253. 
35. Sturm D, Witt H, Hovestadt V, et al. Hotspot mutations in H3F3A and IDH1 define distinct epigenetic and biological subgroups of glioblastoma. Cancer Cell 2012;22:425-437.

36. Khuong-Quang D-A, Buczkowicz P, Rakopoulos P, et al. K27M mutation in histone H3.3 defines clinically and biologically distinct subgroups of pediatric diffuse intrinsic pontine gliomas. Acta Neuropathol 2012;124:439-447.

37. Hou Y, Kohanbash G, Okada K, et al. Novel and shared neoantigen for glioma $\mathrm{T}$ cell therapy derived from histone 3 variant H3.3 K27M mutation. J Immunother Cancer 2015;3:P445.

38. Kohanbash G, Okada K, Liu S, et al. HG-81 novel and shared neoantigen for glioma $\mathrm{T}$ cell therapy derived from histone 3 variant H3.3 K27M mutation. Neuro Oncol 2016;18:iii67.1.

39. Phillips HS, Kharbanda S, Chen R, et al. Molecular subclasses of high-grade glioma predict prognosis, delineate a pattern of disease progression, and resemble stages in neurogenesis. Cancer Cell 2006;9:157-173.

40. Bhat KPL, Balasubramaniyan V, Vaillant B, et al. Mesenchymal differentiation mediated by NF-KB promotes radiation resistance in glioblastoma. Cancer Cell 2013;24:331-346.

41. Verhaak RGW, Hoadley KA, Purdom E, et al. Integrated genomic analysis identifies clinically relevant subtypes of glioblastoma characterized by abnormalities in PDGFRA, IDH1, EGFR, and NF1. Cancer Cell 2010;17:98-110.

42. Noushmehr H, Weisenberger DJ, Diefes K,et al. Identification of a $\mathrm{CpG}$ island methylator phenotype that defines a distinct subgroup of glioma. Cancer Cell 2010;17:510-522.

43. Ceccarelli M, Barthel FP, Malta TM, et al. Molecular profiling reveals biologically discrete subsets and pathways of progression in diffuse glioma. Cell 2016;164:550-563.

44. Gill BJ, Pisapia DJ, Malone HR, et al. MRI-localized biopsies reveal subtype-specific differences in molecular and cellular composition at the margins of glioblastoma. Proc Natl Acad Sci U S A 2014;111:12550-12555.

45. Wang J, Cazzato E, Ladewig E, et al. Clonal evolution of glioblastoma under therapy. Nat Genet 2016;48:768-776.

46. Kozak KR, Mahadevan A, Moody JS. Adult gliosarcoma: epidemiology, natural history, and factors associated with outcome. Neuro Oncol 2009;11:183-191.

47. Han SJ, Yang I, Tihan T, Prados MD, Parsa AT. Primary gliosarcoma: key clinical and pathologic distinctions from glioblastoma with implications as a unique oncologic entity. J Neurooncol 2010;96:313-320.

48. Reis RM, Könü-Lebleblicioglu D, Lopes JM, Kleihues P, Ohgaki H. Genetic profile of gliosarcomas. Am J Pathol 2000;156:425432.

49. Kozak KR, Moody JS. Giant cell glioblastoma: a glioblastoma subtype with distinct epidemiology and superior prognosis. Neuro Oncol 2009;11:833-841.

50. Oh JE, Ohta T, Nonoguchi N, et al. Genetic alterations in gliosarcoma and giant cell glioblastoma. Brain Pathol 2016;26: 517-522.

51. Erson-Omay EZ, Çağlayan AO, Schultz N, et al. Somatic POLEmutations cause an ultramutated giant cell high-grade glioma subtype with better prognosis. Neuro Oncol 2015;17:13561364

52. Domingo E, Freeman-Mills L, Rayner E, et al. Somatic POLE proofreading domain mutation, immune response, and prognosis in colorectal cancer: a retrospective, pooled biomarker study. Lancet Gastroenterol Hepatol 2016;0:207-216.

53. Le DT, Uram JN, Wang H, et al. PD-1 blockade in tumors with mismatch-repair deficiency. N Engl J Med 2015;372:2509-2520.

54. Akimoto J, Namatame H, Haraoka J, Kudo M. Epithelioid glioblastoma: a case report. Brain Tumor Pathol 2005;22:21-27.
55. Kleinschmidt-DeMasters BK, Aisner DL, Birks DK, Foreman NK. Epithelioid GBMs show a high percentage of BRAF V600E mutation. Am J Surg Pathol 2013;37:685-698.

56. Broniscer A, Tatevossian RG, Sabin ND, et al. Clinical, radiological, histological and molecular characteristics of paediatric epithelioid glioblastoma. Neuropathol Appl Neurobiol 2014;40:327336.

57. Makuria AT, Rushing EJ, McGrail KM, Hartmann D-P, Azumi N, Ozdemirli M. Atypical teratoid rhabdoid tumor (AT/RT) in adults: review of four cases. J Neurooncol 2008;88:321-330.

58. Alexandrescu S, Korshunov A, Lai SH, et al. Epithelioid glioblastomas and anaplastic epithelioid pleomorphic xanthoastrocytomassame entity or first cousins? Brain Pathol 2015;26:215-223.

59. Matsumura N, Nakajima N, Yamazaki T, et al. Concurrent TERT promoter and BRAF V600E mutation in epithelioid glioblastoma and concomitant low-grade astrocytoma. Neuropathology 2017;37:58-63.

60. Ida CM, Rodriguez FJ, Burger PC, et al. Pleomorphic xanthoastrocytoma: natural history and long-term follow-up. Brain Pathol 2014:25:575-586.

61. Dias-Santagata D, Lam Q, Vernovsky K, et al. BRAF V600E mutations are common in pleomorphic xanthoastrocytoma: diagnostic and therapeutic implications. PLOS ONE 2011;6:e17948e17949.

62. Schindler G, Capper D, Meyer J, et al. Analysis of BRAF V600E mutation in 1,320 nervous system tumors reveals high mutation frequencies in pleomorphic xanthoastrocytoma, ganglioglioma and extra-cerebellar pilocytic astrocytoma. Acta Neuropathol 2011;121:397-405.

63. Blumke I, Wiestler OD. Gangliogliomas: an intriguing tumor entity associated with focal epilepsies. J Neuropathol Exp Neurol 2002;61:575-584.

64. Gupta K, Orisme W, Harreld JH, et al. Posterior fossa and spinal gangliogliomas form two distinct clinicopathologic and molecular subgroups. Acta Neuropathol Commun 2014;2:18.

65. Dougherty MJ, Santi M, Brose MS, et al. Activating mutations in BRAF characterize a spectrum of pediatric low-grade gliomas. Neuro Oncol 2010;12:621-630.

66. Armstrong TS, Vera-Bolanos E, Bekele BN, Aldape K, Gilbert MR. Adult ependymal tumors: prognosis and the M. D. Anderson Cancer Center experience. Neuro Oncol 2010;12:862870.

67. Wu J, Armstrong TS, Gilbert MR. Biology and management of ependymomas. Neuro Oncol 2016;18:902-913.

68. Ostrom QT, Gittleman H, Liao P, et al. CBTRUS statistical report: primary brain and central nervous system tumors diagnosed in the United States in 2007-2011. Neuro Oncol 2014;16(Suppl. 4):iv163.

69. Merchant PTE, Li C, Xiong PX, Kun PLE, Boop FA, Sanford RA. A prospective study of conformal radiation therapy for pediatric ependymoma. Lancet Oncol 2009;10:258-266.

70. Bouffet E, Tabori U, Huang A, Bartels U. Ependymoma: lessons from the past, prospects for the future. Childs Nerv Syst 2009;25: 1383-1384.

71. Vera-Bolanos E, Aldape K, Yuan Y, et al. Clinical course and progression-free survival of adult intracranial and spinal ependymoma patients. Neuro Oncol 2015;17:440-447.

72. Pajtler KW, Witt H, Sill M, et al. Molecular classification of ependymal tumors across all cns compartments, histopathological grades, and age groups. Cancer Cell 2015;27:728-743.

73. Ebert C, Haken von M, Meyer-Puttlitz B, et al. Molecular genetic analysis of ependymal tumors. NF2 mutations and chromosome $22 \mathrm{q}$ loss occur preferentially in intramedullary spinal ependymomas. Am J Pathol 1999;155:627-632. 
74. Witt H, Mack SC, Ryzhova M, et al. Delineation of two clinically and molecularly distinct subgroups of posterior fossa ependymoma. Cancer Cell 2011;20:143-157.

75. Mack SC, Witt H, Piro RM, et al. Epigenomic alterations define lethal CIMP-positive ependymomas of infancy. Nature 2014;506: 445-450.

76. Parker M, Mohankumar KM, Punchihewa C, et al. C11orf95RELA fusions drive oncogenic NF- $\mathrm{KB}$ signalling in ependymoma. Nature 2014;506:451-455.

77. Forment JV, Kaidi A, Jackson SP. Chromothripsis and cancer: causes and consequences of chromosome shattering. Nat Rev Cancer 2012;12:663-670.

78. Choi C, Ganji SK, DeBerardinis RJ, et al. 2-hydroxyglutarate detection by magnetic resonance spectroscopy in IDH-mutated patients with gliomas. Nat Med 2012;18:624-629.

79. Pope WB, Prins RM, Albert Thomas M, et al. Non-invasive detection of 2-hydroxyglutarate and other metabolites in IDH1 mutant glioma patients using magnetic resonance spectroscopy. J Neurooncol 2012;107:197-205.

80. Beiko J, Suki D, Hess KR, et al. IDH1 mutant malignant astrocytomas are more amenable to surgical resection and have a survival benefit associated with maximal surgical resection. Neuro Oncol 2013;16:81-91.

81. Andronesi OC, Rapalino O, Gerstner E, et al. Detection of oncogenic IDH1 mutations using magnetic resonance spectroscopy of 2-hydroxyglutarate. J Clin Invest 2013;123:3659-3663.

82. Behling F, Barrantes-Freer A, Skardelly M, et al. Frequency of BRAF V600E mutations in 969 central nervous system neoplasms. Diagn Pathol 2016;11:55.

83. Buczkowicz P, Bartels U, Bouffet E, Becher O, Hawkins C. Histopathological spectrum of paediatric diffuse intrinsic pontine glioma: diagnostic and therapeutic implications. Acta Neuropathol 2014;128:573-581.

84. Jones C, Karajannis MA, Jones DTW, et al. Pediatric high-grade glioma: biologically and clinically in need of new thinking. Neuro Oncol 2016 Jun 9 [Epub ahead of print].

85. Chinot OL, Wick W, Mason W, et al. Bevacizumab plus radiotherapy-temozolomide for newly diagnosed glioblastoma. N Engl J Med 2014;370:709-722.

86. Sandmann T, Bourgon R, Garcia J, et al. Patients with proneural glioblastoma may derive overall survival benefit from the addition of bevacizumab to first-line radiotherapy and temozolomide: retrospective analysis of the AVAglio trial. J Clin Oncol 2015;33: 2735-2744.

87. Liu P, Cheng H, Roberts TM, Zhao JJ. Targeting the phosphoinositide 3-kinase pathway in cancer. Nat Rev Drug Discov 2009;8:627-644.

88. Heimberger AB, Hlatky R, Suki D, et al. Prognostic effect of epidermal growth factor receptor and EGFRvIII in glioblastoma multiforme patients. Clin Cancer Res 2005;11: 1462-1466.

89. Raizer JJ, Abrey LE, Lassman AB, et al. A phase II trial of erlotinib in patients with recurrent malignant gliomas and nonprogressive glioblastoma multiforme postradiation therapy. Neuro Oncol 2010;12:95-103.

90. Uhm JH, Ballman KV, Wu W, et al. Phase II evaluation of gefitinib in patients with newly diagnosed grade 4 astrocytoma: Mayo/ North Central Cancer Treatment Group Study N0074. Int J Radiat Oncol Biol Phys 2011;80:347-353.

91. Hasselbalch B, Lassen U, Hansen S, et al. Cetuximab, bevacizumab, and irinotecan for patients with primary glioblastoma and progression after radiation therapy and temozolomide: a phase II trial. Neuro Oncol 2010;12:508-516.
92. Malkki H. Trial Watch: glioblastoma vaccine therapy disappointment in Phase III trial. Nat Rev Neurol 2016;12:190.

93. Taylor TE, Furnari FB, Cavenee WK. Targeting EGFR for treatment of glioblastoma: molecular basis to overcome resistance. Curr Cancer Drug Targets 2012;12:197-209.

94. Radiation Therapy Oncology Group. A study of ABT-414 in subjects with newly diagnosed glioblastoma (GBM) with epidermal growth factor receptor (EGFR) amplification (intellance 1). Available at: https://clinicaltrials.gov/ct2/show/NCT02573324. Accessed 24 October 2016.

95. Johnson LA, Scholler J, Ohkuri T, et al. Rational development and characterization of humanized anti-EGFR variant III chimeric antigen receptor T cells for glioblastoma. Sci Transl Med 2015;7:275ra22.

96. Gupta SK, Kizilbash SH, Carlson BL, et al. Delineation of MGMT hypermethylation as a biomarker for veliparib-mediated temozolomide-sensitizing therapy of glioblastoma. J Natl Cancer Inst 2015;108.

97. Schumacher T, Bunse L, Pusch S, et al. A vaccine targeting mutant IDH1 induces antitumour immunity. Nature 2014;512:324-327.

98. Seltzer MJ, Bennett BD, Joshi AD, et al. Inhibition of glutaminase preferentially slows growth of glioma cells with mutant IDH1. Cancer Res 2010;70:8981-8987.

99. Wan PTC, Garnett MJ, Roe SM, et al. Mechanism of activation of the RAF-ERK Signaling pathway by oncogenic mutations of BRAF. Cell 2004;116:855-867.

100. Davies H, Bignell GR, Cox C, et al. Mutations of the BRAF gene in human cancer. Nature 2002;417:949-954.

101. Chapman PB, Hauschild A, Robert C, et al. Improved survival with vemurafenib in melanoma with BRAF V600E mutation. N Engl J Med 2011;364:2507-2516.

102. Chamberlain MC. Recurrent ganglioglioma in adults treated with BRAF inhibitors. CNS Oncol 2016;5:27-29.

103. Rush S, Foreman N, Liu A. Brainstem ganglioglioma successfully treated with vemurafenib. J Clin Oncol 2013;31:e159-e160.

104. del Bufalo F, Carai A, Figà-Talamanca L, et al. Response of recurrent BRAFV600E mutated ganglioglioma to Vemurafenib as single agent. J Transl Med 2014;12:356.

105. Aguilera D, Janss A, Mazewski C, et al. Successful retreatment of a child with a refractory brainstem ganglioglioma with vemurafenib. Pediatr Blood Cancer 2015;63:541-543.

106. Kleinschmidt-DeMasters BK, Aisner DL, Foreman NK. BRAF VE1 immunoreactivity patterns in epithelioid glioblastomas positive for BRAF V600E mutation. Am J Surg Pathol 2015;39:528540.

107. Robinson GW, Orr BA, Gajjar A. Complete clinical regression of a BRAF V600E-mutant pediatric glioblastoma multiforme after BRAF inhibitor therapy. BMC Cancer 2014;14:397.

108. Skrypek M, Foreman N, Guillaume D, Moertel C. Pilomyxoid astrocytoma treated successfully with vemurafenib. Pediatr Blood Cancer 2014;61:2099-2100.

109. Lee EQ, Ruland S, LeBoeuf NR, Wen PY, Santagata S. Successful treatment of a progressive BRAF V600E-mutated anaplastic pleomorphic xanthoastrocytoma with vemurafenib monotherapy. J Clin Oncol 2016;34:e87-e89.

110. Chamberlain MC. Salvage therapy with BRAF inhibitors for recurrent pleomorphic xanthoastrocytoma: a retrospective case series. J Neuro Oncol 2013;114:237-240.

111. Johnson BE, Mazor T, Hong C, et al. Mutational analysis reveals the origin and therapy-driven evolution of recurrent glioma. Science 2014;343:189-193.

112. van Thuijl HF, Mazor T, Johnson BE, et al. Evolution of DNA repair defects during malignant progression of low-grade gliomas after temozolomide treatment. Acta Neuropathol 2015;129:597607. 